Vol.: 4 Issue: 2 Date: 31.12.2020 Received: 14.12.2020 Accepted: 28.12.2020 Final Version: 30.12.2020

ISVOS Journal, 2020, 4(2): 97-110 - https://doi.org/10.47897/bilmes.840471

\title{
Modeling of 2D Functionally Graded Circular Plates with Artificial Neural Network
}

\author{
Munise Didem Demirbaş ${ }^{\mathrm{a}}{ }^{1}$, Didem Çakır ${ }^{\mathrm{b}}$

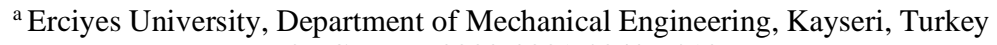 \\ ORCID ID: 0000-0001-8043-6813 \\ ${ }^{\mathrm{b}}$ Erciyes University, Institute of Science and Technology, Kayseri, Turkey
}

ORCID ID: 0000-0001-7682-6923

\begin{abstract}
The thermo-mechanical properties of the functionally graded material (FGM) depend on the volumetric distribution that determines the material character, which is very important in order to overcome different operating conditions and stress levels. Three different training algorithms are used in an Artificial Neural Network (ANN) to determine the equivalent stress levels of a hollow disc that is functionally graded in two directions. The data set was created by choosing the most important four different equivalent stress values ( $\sigma$ (eqv max max) , $\sigma_{-}$(eqv max min) , $\sigma_{-}$(eqv $\min \max ), \sigma_{-}($eqv min min)) that determine the material structure in thermo-mechanical analysis. Performance estimation was performed in three different training algorithms (Gradient Descent Backpropagation, Gradient Descent with Momentum Backpropagation, BFGS QuasiNewton Backpropagation Algorithm). In this study, termomechanical behaviour was numerically determined by using finite difference method at different compositional gradient upper values to train ANN.
\end{abstract}

Keywords: "Two-directional functionally graded circular plates, finite difference method, thermal stress analysis , artificial neural network, training algorithms"

\section{Giriş}

Malzeme teknolojisinde temel elementlerden alaşım, seramik ve kompozitler gibi konsolide malzeme geliştirilmesi ile klasik mekanikten daha karmaşı 3 boyutta ağır koşullarda çalışan sistemlere geçişte mekanik ve termal malzeme mukavemeti sağlanmıştır. Günümüzde bilgisayar teknolojisi ve analiz yöntemlerinin gelişmesi ile istenilen çalışma aralı̆̆ı, tolerans değeri ve hassasiyette makro-mikro-nano yapıda makine malzemesi üretilerek maksimum verimlilik sağlanmıştır. Bilgisayar bilimleri ve yapay zeka uygulamalarının ilerlemesi ile kestirimsel malzeme davranışları ve ileri teknoloji malzeme kompozisyonunun belirlenmesi mümkün olmuştur. Bu teknolojik malzemelerden biri de özellikle yüksek sıcaklık uygulamalarında kullanılan bir tarafı metal diğer tarafı seramik, metalden seramiğe geçişi belirli bir hacimsel fonksiyona göre belirlenen Fonksiyonel Kademeli Malzemeler (FKM)'dir. FKM ile metal ve seramik malzemeler birleşim yerlerinde ara yüzey çatlakları ve artık gerilmeler engellenmiştir [1-4].

Literatürde yapılan çalışmalarda termo-mekanik karakteri ve belirli sınır şartları altında malzeme çalışma koşullarını belirleyen kompozisyonel gradyant üst değerinin tayin edilmesine odaklanılmıştır. Koşullara ayak uyduracak optimum malzeme dağılımını bulmak için sayısal analiz yöntemlerini kullanarak Sürü Optimizasyonları, Genetik Programlama (GP) veya Yapay Sinir Ağı (YSA) gibi sezgisel optimizasyon yöntemlerinde farklı tasarım modelleri denenmiştir. Literatürde yer alan bazı çalışmalar aşağıda detaylandırılmıştır.

Wang ve arkadaşları [5] statik yüklemeye karşı FKM plakarda yeni bir makine öğrenimi tabanlı yapısal güvenilirlik analizi yöntemi geliştirdiler. Önerilen yarı simülatif yöntemin yapısal tasarım ve değerlendirmelerde uygulanabilir ve verimli olduğunu belirttiler. Do ve arkadaşları [6], 3-D FKM serbest titreşimi ve burkulmayı amaç fonksiyonu kabul ederek Derin Sinir Ağı ve İzogeometrik Çok Zamanlı Tasarım ile malzeme optimizasyonu üzerine çalıştılar. Bulunan değerlerin literatürde yer alan diğer çalışmalara yakın olduğunu belirterek daha karmaşı mühendislik problemlerinde kullanılabileceğini belirttiler. Ghatage ve arkadaşları [7], FKM'lerin çok yönlü gelişmeye açık bir malzeme olduğunu, doğru modelleme ve analiz ile gereksinimleri karşılayacağını belirtiler. İnsan sağlı̆̆ için önem arz eden özellikle medikal uygulamalar için gerekli olan FKM'lerin lineer

\footnotetext{
${ }^{1}$ Corresponding author. Tel.: +095458358475

E-mail address: mddemirbas@erciyes.edu.tr
} 
olmayan yüklemeler altındaki davranış analizlerinin sınırlı olduğuna değindiler. Gelecekte yapılacak çalışmaların yeni analiz yöntemleri kullanılarak uygulanabilirlikleri açısından faydalı olabileceğini belirttiler. Karsh ve arkadaşları [8], sonlu elemanlar yöntemini kullanarak FKM’lerin YSA ‘da stokastik dinamik analizini yaptılar. Sonlu elemanlar yöntemiyle kurulan modelin Monte Carlo simülasyonuna göre doğrulamasını yaparak YSA tabanlı algoritmanın, sonuçları doğru hesapladığını belirttiler. Dikici ve Tuntas [9], bir Al / TiC FKM'nin zamanla sertleşme ve korozyon davranışını giriş parametreleri kompozit katmanların TiC hacim fraksiyonu, kompozitin yaşlanma süreleri, çevresel koşullar ve korozyon testleri sırasında uygulanan yük ve çıış değeri yoğunluk ve mikro sertlik olacak şekilde YSA'da araştırdılar. Deneysel sonuçların yapılan çalışmalarla yakınsadığını belirttiler. Mantari ve Monge [10] FKM plakalarda mekanik yüklemede malzemenin serbest titreşim ve burkulma davranışının gözlemlediler. FKM'lerin burkulma analizini kalınlık yönünden değerlendirerek optimizasyon yöntemi önerdiler. Yöntemin yüksek doğrulukta sonuca ulaştı̆̆ını belirttiler. Nazari ve arkadaşları [11] FKM'lerin çekirdek ve kalınlık üzerindeki doğal frekansını gerçek değerlere yakın bir şekilde Meshless Local Petrov-Galerkin (MLPG) yöntemi ile uygulayarak YSA yönteminde optimum değeri sundular. Jodaei ve arkadaşları [12] 3-D FKM dairesel plakaların sayısal analizi için state-space based differential quadrature metodunda (SSDQM) ,YSA algoritmasını kullandılar. YSA'da FKM plakalar için yeni bir tasarım modeli oluşturdular. Cho ve Ha [13] FKM'lerin termoelastik davranışını, sonlu farklar metodunu kullanarak analiz ettiler. Farklı sınır şartları için 2-D hacimsel dağılımın optimum değerini araştırdılar. Ara yüzeylerdeki en yüksek gerilmeyi minimize etmek için YSA kullandılar. Na ve Kim [14] 3-D FKM'de termo-mekanik burkulma analizi için kompozisyonel gradyant üst değerini araştırarak sonlu elemanlar metodu ile malzemede oluşan gerilme dağılımını optimum yapacak en uygun hacimsel dağılımı ifade ettiler. Cho ve Shin [15] YSA'yı kullanarak 1sıya dayanıklı malzeme bilişiminin optimizasyonu üzerine çalıştılar. İç ceza fonksiyonu ve altın oran yöntemini optimizasyonda kullandılar. Sayısal deneyler sonucunda, YSA'nın malzeme optimizasyonunda optimum tasarıma ulaşmada etkin olduğunu sundular.

Literatürde FKM'lerin malzeme kompozisyonunu belirleyen kompozisyonel gradyant üst değerinin optimizasyonu veya tahmini için pek çok çalışma yapılmaktadır. Kompozisyonel gradyant üst değerinin optimizasyonu ile arzu edilen malzeme davranışı sağlanabilmektedir. YSA ve GP gibi literatürde sıkça yer alan yöntemlerin yanı sıra farklı efektif optimizasyon yöntemleri ile yüksek nitelikli FKM tasarım çalışmaları devam etmektedir [16-20].

\section{Materyal ve Metot}

\subsection{Fonksiyonel Kademelendirilmiş Malzemeler ve Dairesel Plaka}

Günümüz statik/dinamik sistemlerinde termal dayanımı yüksek malzeme üretimi sistemlerin güvenliği için oldukça önem kazanmıştır. Gelişen bilgisayar bilimleri ve analiz yöntemleri ile mevcut malzemelerde iyileştirme ve geliştirme olanakları artmış böylelikle özgün malzemeler üretilmiştir. Geliştirilmiş bu özel malzemelerden biri de FKM'dir. Bu malzemelerde bileşimin bir hacim fonksiyonuna bağlı olarak değiştirilmesi ile kademeli bir malzeme geçişi sağlanır bu geçiş sayesinde standart üretilmiş malzemelerden farklı olarak geçiş bölgesindeki süreksizlikler ve buna bağlı olarak meydana gelen yapısal kusurlar ve ara yüzey çatlakları minimum düzeye indirgenebilir. İstenilen özelliklerin sağlanması için en uygun hacimsel dağılımı belirlerken verimlilik, performans ve iyileştirilmiş termo-mekanik özellikler göz önünde tutulabilmektedir. Bu özellikler optimum hacimsel dağılım ve dolayısıyla kompozisyonel gradyant üst değerinin belirlenmesi ile mümkündür.

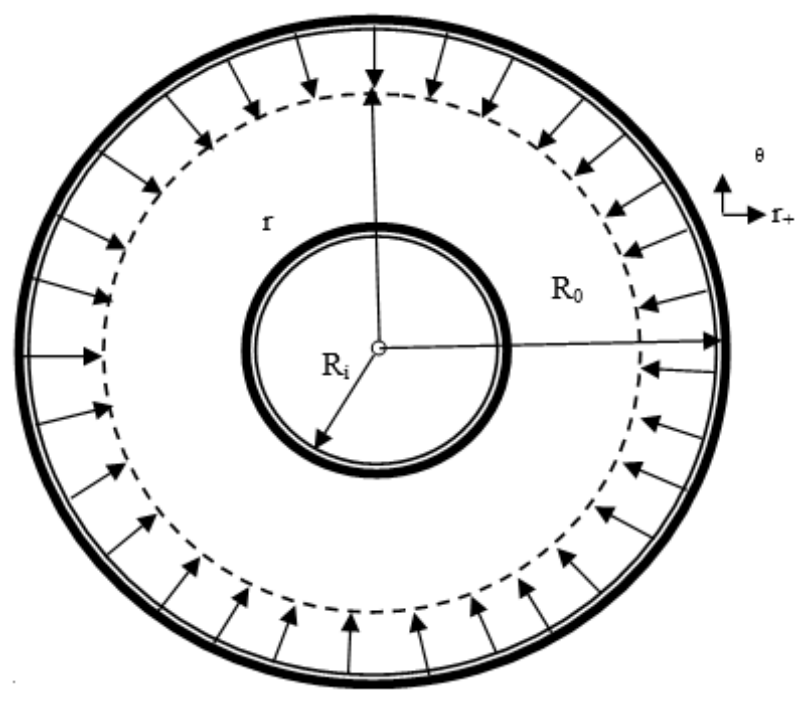

Şekil 1. Fonksiyonel kademelendirilmiş dairesel plaka [21] 
Şekil 1'de Fonksiyonel kademelendirilmiş dairesel plakanın radyal yönde kademelendirilmesi gösterilmiştir. Bu kademelendirilme ise aşağıdaki Seramik malzemenin hacimsel dağılımını gösteren formül ile gerçekleştirilmiştir.

$$
\begin{gathered}
V_{s}^{r}(\bar{r})=\left(\frac{\bar{r}}{l_{R}}\right)^{n} \\
V_{s}^{\theta}(\theta)=(|\sin (p \theta)|)^{m}
\end{gathered}
$$

$\mathrm{R}_{\mathrm{o}}$ ve $\mathrm{R}_{\mathrm{i}}$ sırasıyla plakanın dış ve iç yarıçapı olup $\bar{r}=r-R_{i}, l_{R}=\mathrm{R}_{\mathrm{o}}-\mathrm{R}_{\mathrm{i}}{ }^{\prime}$ dir ve $\mathrm{Vs}$, seramik hacim oranını vermektedir. Plakadaki radyal yöndeki seramik hacimsel oranı denklem 1'de ve teğetsel yöndeki seramik hacimsel oran denklem 2'de vermektedir. $\mathbf{V}_{\mathbf{m}}$ metal hacimsel dağılımını gösteren denklem 4'te ulaşılmaktadır [27];

$$
\begin{aligned}
& V_{s}(\bar{r}, \theta)=V_{s}^{r}(\bar{r}) \cdot V_{s}^{\theta}(\theta) \\
& V_{m}(\bar{r}, \theta)=1-V_{s}(\bar{r}, \theta)
\end{aligned}
$$

Plakanın hacim oranlarına bağlı olarak termal ve mekanik özellikleri Mori-Tanaka [26] şeması esas alınarak belirlenmiştir. Daha önceki çalışmalarımızda formülasyonlar vardır [21,23-25].

\subsection{Yapay Sinir A $\breve{g} ı$ Algoritması}

Optimizasyon yöntemleri doğadaki canlıların yaşayış ve işleyiş şekillerinden uyarlanarak tasarlanmıştır. Yönetimsel süreçler göz önünde tutularak bunların en iyi araması ve en uygun sonuca ulaşması gözlemlenmiştir. Bunların sonucunda insan beyninin çalışma prensipleri, bilgiyi iletme şekli ve tercih etme süreçlerinin aşamaları düşünülerek yapay sinir ağı modelleri ortaya çıkmıştır. Bu işleyiş sürecinde bilgilerin alınması, değerlendirilmesi, durumun kaydedilmesi ve sonuca ulaşması aşamaları bulunmaktadır.

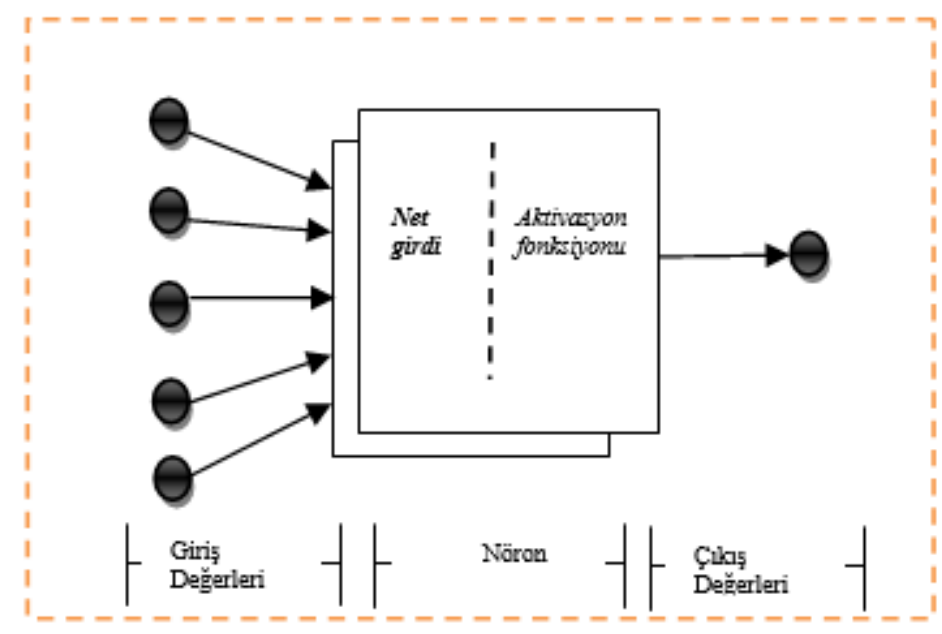

Şekil 2. YSA'nın basit bir nöron işleyiş modeli

Bir veya birden fazla giriş ve çıkış değeri olan lineer ya da non-lineer problem çözümlerinde aktif olarak kullanılmaktadır. YSA'nın kuruluş mantığına göre giriş değerleri, nöron ve çıkış değerleri arasındaki işlemlerle modeller kurulur. Şekil 2'de YSA'daki basit bir nöronun işleyiş durumu gösterilmiştir. Nöronlara gelen giriş değerleri denklem 4'de belirtilen kümülatif toplam fonksiyonunda kullanılarak net girdi oluşturulur ve denklem 5'de yer alan aktivasyon fonksiyonuna gönderilir. Aktivasyon fonksiyonu non-lineer fonksiyon olarak tercih edilir çalışmamızda bunların arasında yaygın olarak kullanılan sigmoid fonksiyonu tercih edilmiştir. Denklem 4'de x giriş, w ağırlık ve b eşik değerini simgelemektedir.

$$
\begin{aligned}
& \text { net girdi }=\sum_{m=1}^{m}\left(x_{i} * w_{i}+b_{i}\right) \\
& f(\text { net girdi })=\frac{1}{1+e^{- \text {net girdi }}}
\end{aligned}
$$

$\mathrm{Bu}$ işlemlerin sonucunda tahmini çıktı değerlerine ulaşılır. Tahmini değerler ile gerçek değerler arasındaki yakınsamayı ölçmek için bir hata değeri hesaplama fonksiyonu belirlenir. Denklem 6'da ortalama karesel hata fonksiyonu ile hata değerleri gösterilmiştir. Denklem 6' da $\mathrm{y}_{\mathrm{d}}$ tahmini ve y de gerçek değerleridir. 


$$
e=\frac{1}{2} \sum_{m=1}^{m}\left(y_{d}-y\right)^{2}
$$

Problemimizin aşağıda belirtilen 3 farklı eğitim algoritması ile modelleri kurulmuş ve değerlendirilmiştir.

Geriye Yayılım Algoritması (Gradient Descent Backpropagation ) Geriye Yayılım, yapay sinir ağının çoğunlukla kullandığı bir öğrenme algoritmasıdır. Öğrenme sürecinde her nöronda gradyant azaltma tekniğini uygular. Rumelhart ile McClelland tarafından önerilen ve ilk olarak Werbos tarafında geliştirilen yöntem, çıkış değerlerinden giriş değerlerine doğru hata değerlerini azaltma işlemi yaptığı için geriye yayılım algoritması denmiştir [28]. Doğrusal olmayan programda hata oranları ve ağırlıklar kısmı türevleri üzerinden gerçekleşir tahmini değerlerin gerçeğe yakınsaması beklenir. Bu algoritma, kuruluş mantığına göre ilk koşullara duyarlıdır, yakınsama hızı yavaş ve yerel minimuma takılma olasılığı vardır. Eğer ilk atanan ağırlık vektörleri hata düzeyine yakınsa öğrenme durumu hızlı olacaktır. Fakat tam tersi durum da olabilir. Öğrenme katsayısı " $n$ ”, olup 0.1-0.9 arasında bir değer verilir [29-30]. Geriye yayılım algoritması denklem 7'de gösterilmiştir.

$$
w_{i j}=w_{i j-1}+n\left(\frac{\partial e_{i j}}{\partial w_{i j-1}}\right)
$$

Momentum Katsayılı Geriye Yayılım Algoritması (Gradient Descent with Momentum Backpropagation) Geriye Yayılım Algoritması'nın ilk koşullara takılmasını önlemek için Rumelthart tarafından momentum kat sayısı eklenerek geliştirilmiştir ve güncellenen fonksiyon denklem 8'de gösterilmektedir. Burada $\alpha$ momentum katsayısıdır [31].

$$
w_{t}=w_{t-1}+n\left(\frac{\partial E_{t}}{\partial w_{t-1}}\right)+\alpha \Delta w_{t-1}
$$

Quasi-Newton Algoritması (BFGS Quasi-Newton Backpropagation) ‘nda hatanın, ağırlıklara göre ikinci derecede türeviyle oluşan Hessian matrisi kullanılarak işlem yapılır. Denklem 9 'da olan Hessian matrisi ağırlık uzayının farklı doğrultuda gradyant değişimini gösterir. Eşleşmeli gradyant algoritmalarına göre daha hızlıdır. Ağırlık güncelleme işlemi denklem 10 'da gösterilmektedir [32].

$$
\begin{gathered}
H_{t}=\frac{\partial^{2} E_{t}}{\partial w_{t-1}{ }^{2}} \\
w_{t}=w_{t-1}+\eta H_{t}^{-1} \frac{\partial E_{t}}{\partial w_{t-1}}
\end{gathered}
$$

\section{Problem Tarifi ve YSA ile Modelleme}

\subsection{Problemin Tarifi}

Dairesel plakanın dış kenarı boyunca düzlem içi sabit $200 \mathrm{KW} / \mathrm{m}^{2}$ 1sı akısında maruz bırakılıp iç ve dış kenarı sabit tutularak termal gerilme analizleri sonlu fark denklemleri ile Elastisite Teorisi kullanılarak yapılmıştır. Plakamızın kalınlığı belirlediğimiz boyutlara göre ihmal edilebilecek seviyede olduğu için Elastisite Teorisi denklemleri iki boyutlu olarak çözülmüştür. İki yönde kademelendirilen dairesel plakanın bileşenleri seramik $\left(\mathrm{ZrO}_{2}\right)$ ve metal (Ti-6Al-4V) olarak tercih edilmiştir. Dairesel plakanın Termo mekanik davranışını belirleyen eş değer gerilme seviyeleri esas alınarak YSA modelleri değerlendirilmiştir. Eşdeğer gerilme değerleri arasında en önemli olan en büyük değerinin en büyüğü, en büyük değerinin en küçügü, en küçük değerinin en büyüğü ve en küçük değerinin en küçüğü seçilerek farklı kompozisyonel gradyant üst değerleri için YSA modelleri kurulmuştur.

\subsection{YSA ile modelleme}

Sonlu farklar metodu ile yaptığımız analiz çalışmaları sonucunda 40 farklı kompozisyonel gradyant üst değerlerine ulaşılmıştır. Kompozisyonel gradyant üst değerleri yani n ve m değeri [0.1-1] aralığında sınırlandırılmıştır. Bu verileri YSA'da kullanmak üzere iki giriş ve dört çıkışlı olacak şekilde $V_{40,6}$ ' lık bir matris oluşturularak veri seti yapılmıştır. Bu matrisin ilk iki sütunu giriş verileri, son dört sütunu ise çıkış verileri olarak Matlab [22]'da kurduğumuz koda tanıtılmıştır. Rassal dağılacak bir şekilde oluşturulan veri seti \%50 eğitim ,\%50 test verisi olarak bölünmüştür. Programımızın durdurma kriteri verilerdeki doğrulama oranının \%10 olmas1 ve maksimum çevrim sayısının 1000 olması olarak belirlenmiştir. Şekil 3.' de görüldüğü gibi YSA modelimizde 3 farklı eğitim algoritması kullanılarak iki giriş, dört çıkış ve üç nörondan oluşan tek katmanlı algılayıcı model oluşturulmuştur. 


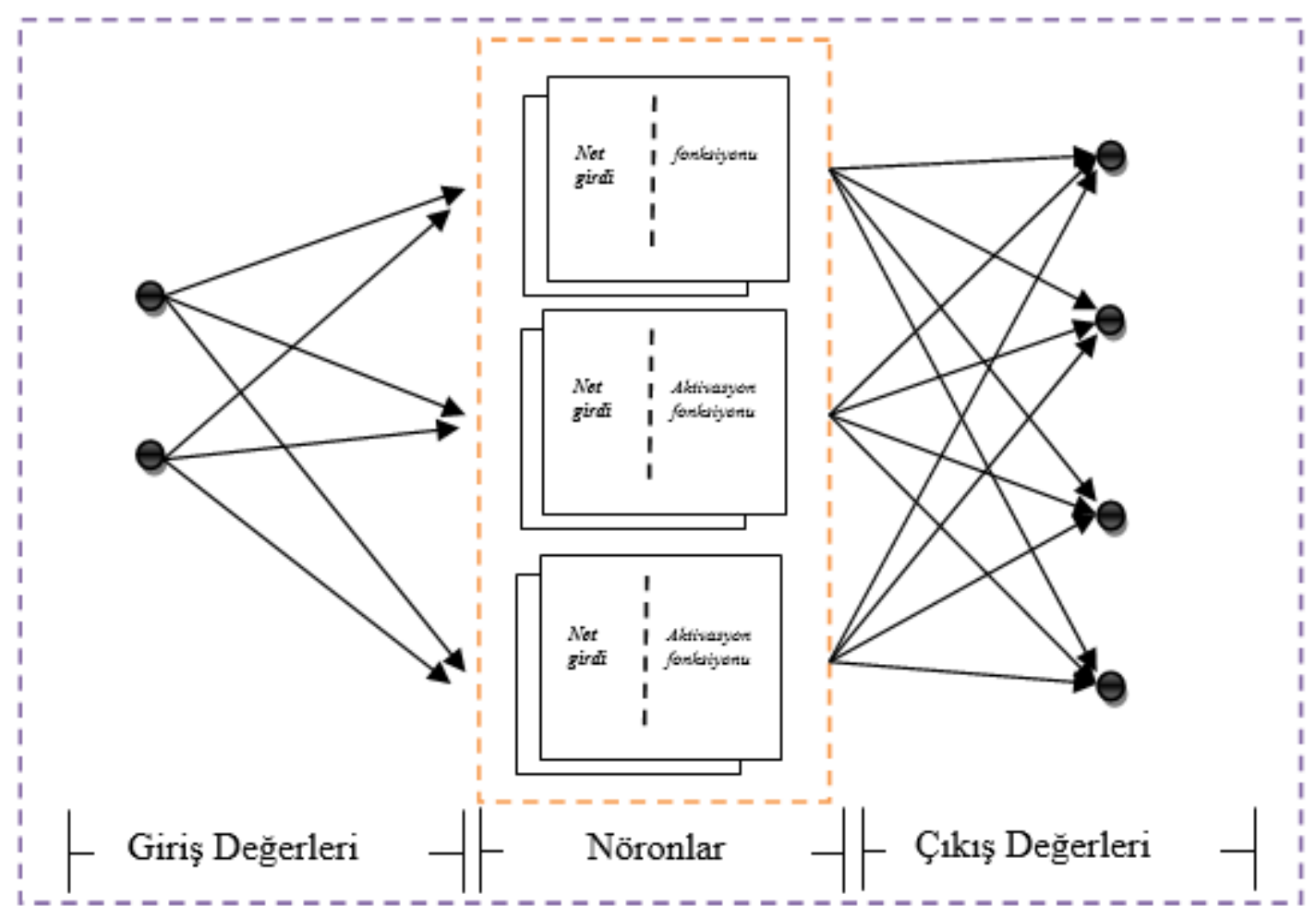

Şekil 3. Tek katmanlı yapay sinir ağı modeli

Geriye Yayılım algoritmasında eğitilmiş model incelendiğinde eğitim aşamasında çıkan tahmini değerlerin gerçek değerlere yaklaşık \% 70 oranında bir doğrulukta çözdüğü görülmektedir. Dahası eğitilmiş modelin test değerlerleri ile yaptığı analizde ise bu oran \%55'e gerilemiştir. Programın grafiksel çıktısı şekil 4'de görülmektedir.
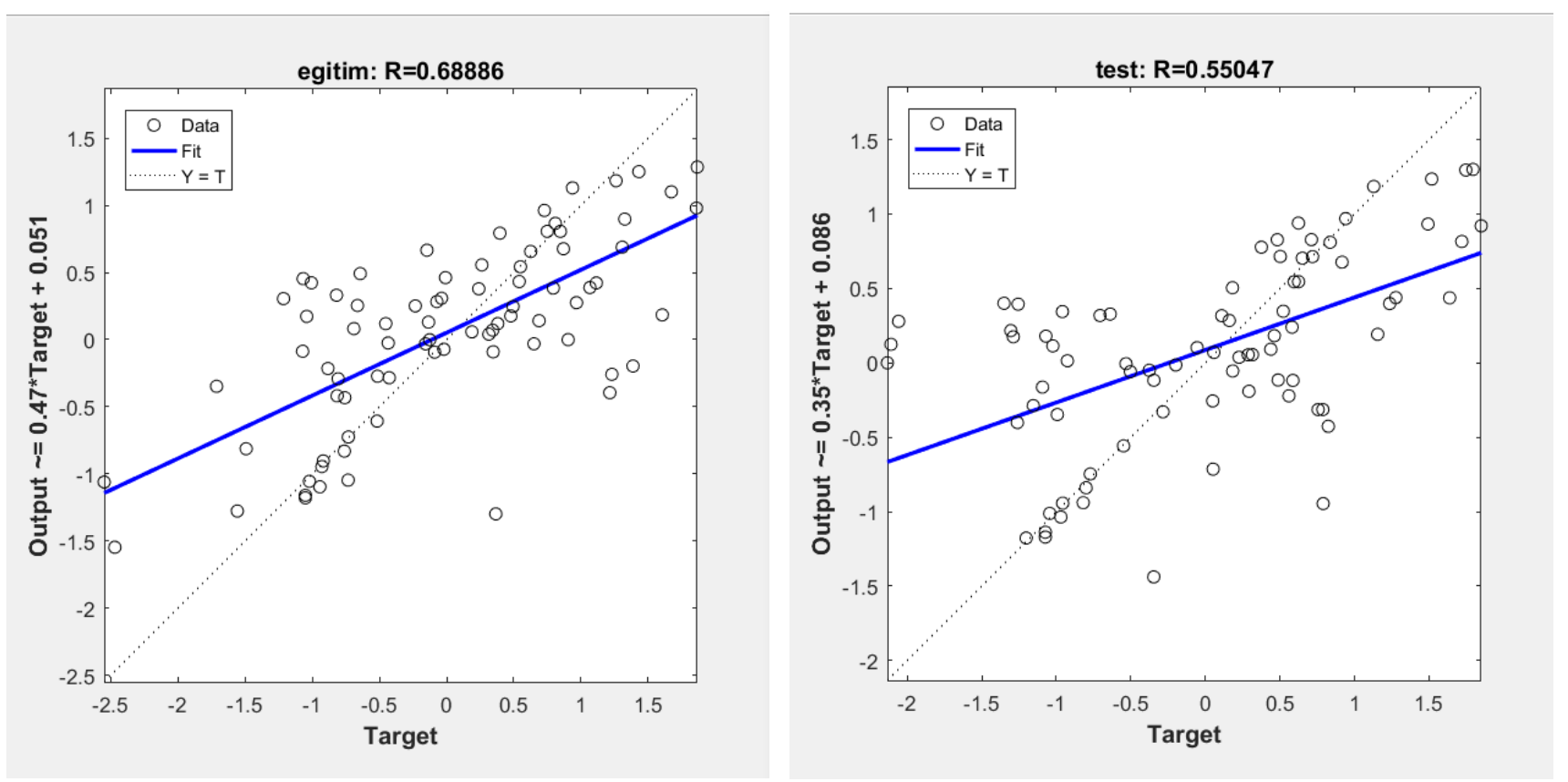

Şekil 4. Geriye Yayılım algoritmasının eğitilen model için tahmin değerleri 


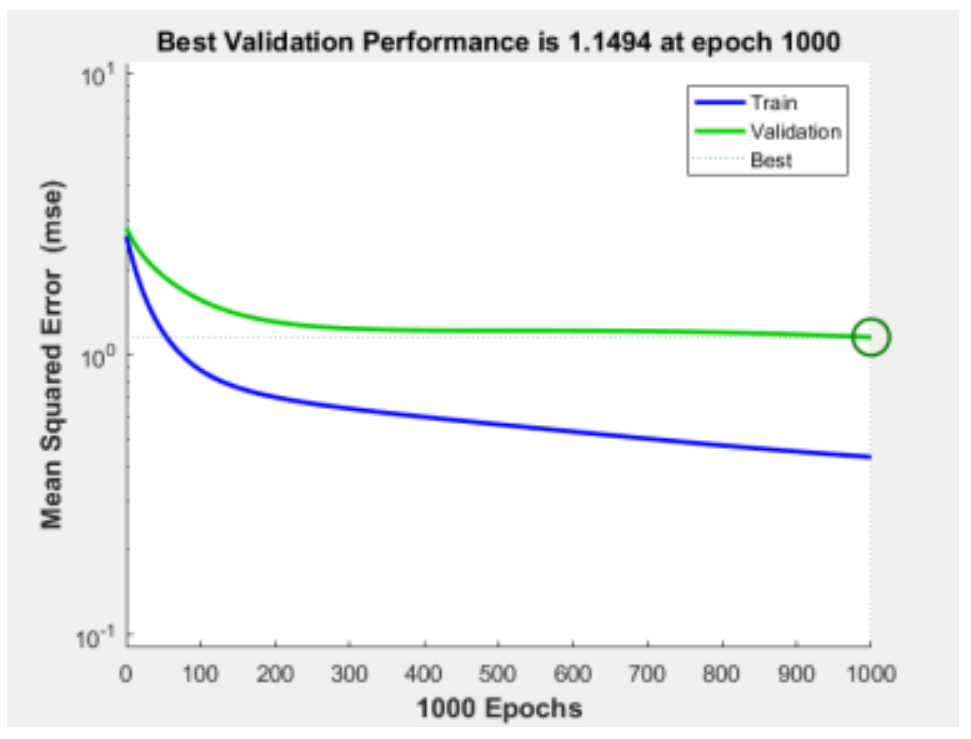

Şekil 5. Geriye Yayılım algoritmasının eğitilen model için doğrulama performansı

Şekil 5'te YSA'da Geriye Yayılım algoritmasında eğitilmiş modelin en küçük kareler (MSE) yönteminde hesaplanmış minimum hata değerini göstermektedir. Burada çevrim sayısı arttıkça eğitim ile doğrulama tahmininin hata değeri arasındaki fark artmaktadır. En iyi doğrulama performansı ise 1000 çevrim için 1.1494' tür.

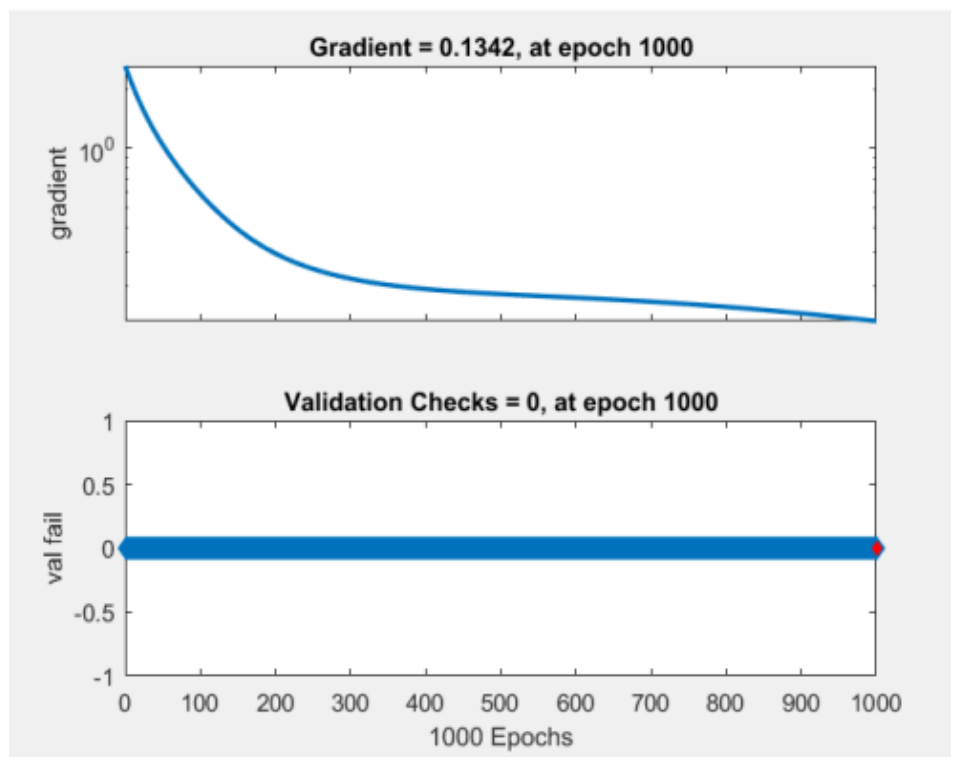

Şekil 6. Geriye Yayılım algoritmasının eğitilen model için gradyant ve başarısız doğrulamanın çevrim sayısına bağlı değişimi

Şekil 6'da Geriye Yayılım algoritması ile eğitilen model için gradyant ve başarısız doğrulamanın çevrim sayısına bağlı değişimini göstermektedir. Burada maksimum çevrim sayısı 1000 olmak üzere gradyant 0,1342 ve başarısız doğrulama 0’dır. 

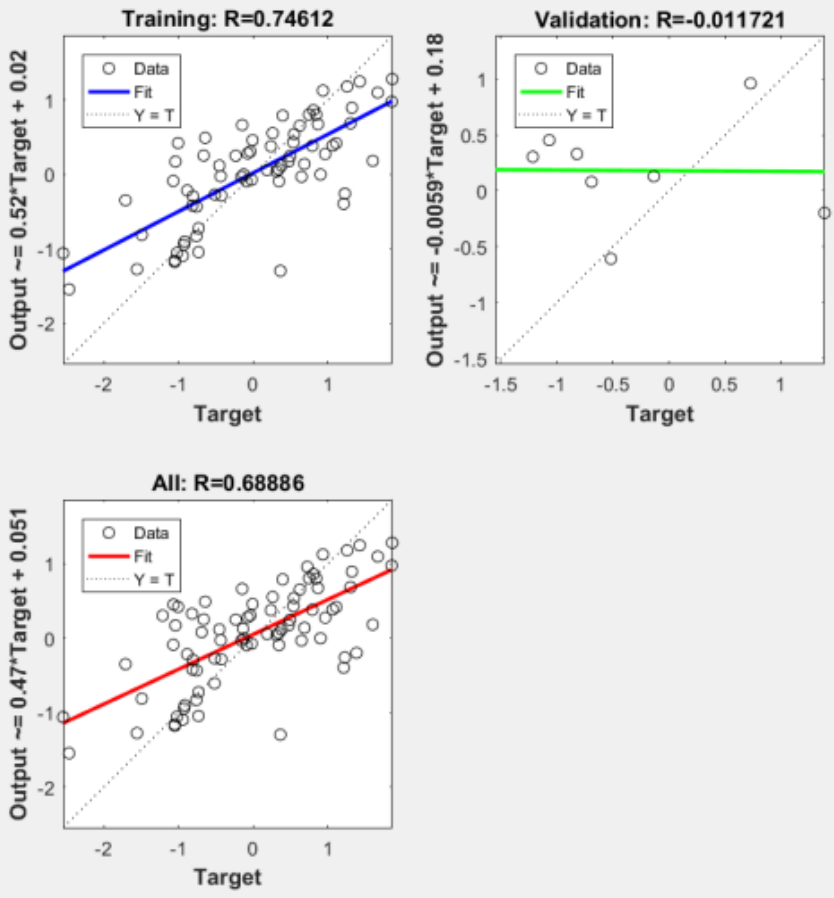

Şekil 7. Geriye Yayılım algoritmasının eğitilen model için tüm tahmin değerleri

Şekil 7'de Geriye Yayılım algoritması ile eğitilen yapay sinir ağının modelinin tahmin değerlerini gösterilmektedir. Burada eğitim için tahmin değeri 0.74612 , doğrulama için tahmin değeri 0.011721 ve toplam tahmin değeri 0.68886 olup eğitilmiş modelin performansı arzu edilen seviyeye ulaşamamıştır.

İkinci eğitim algoritmamız olan Momentum Katsayılı Geriye Yayılım algoritması kullanılarak oluşturduğumuz modelin eğitim aşamasında oluşturduğu tahmini değerleri yaklaşık \%57 ve modelin test aşamasındaki performansı ise $\% 49$ olmuştur. Şekil 8'de modelin eğitim ve test değerlerinin performansları gösterilmektedir.
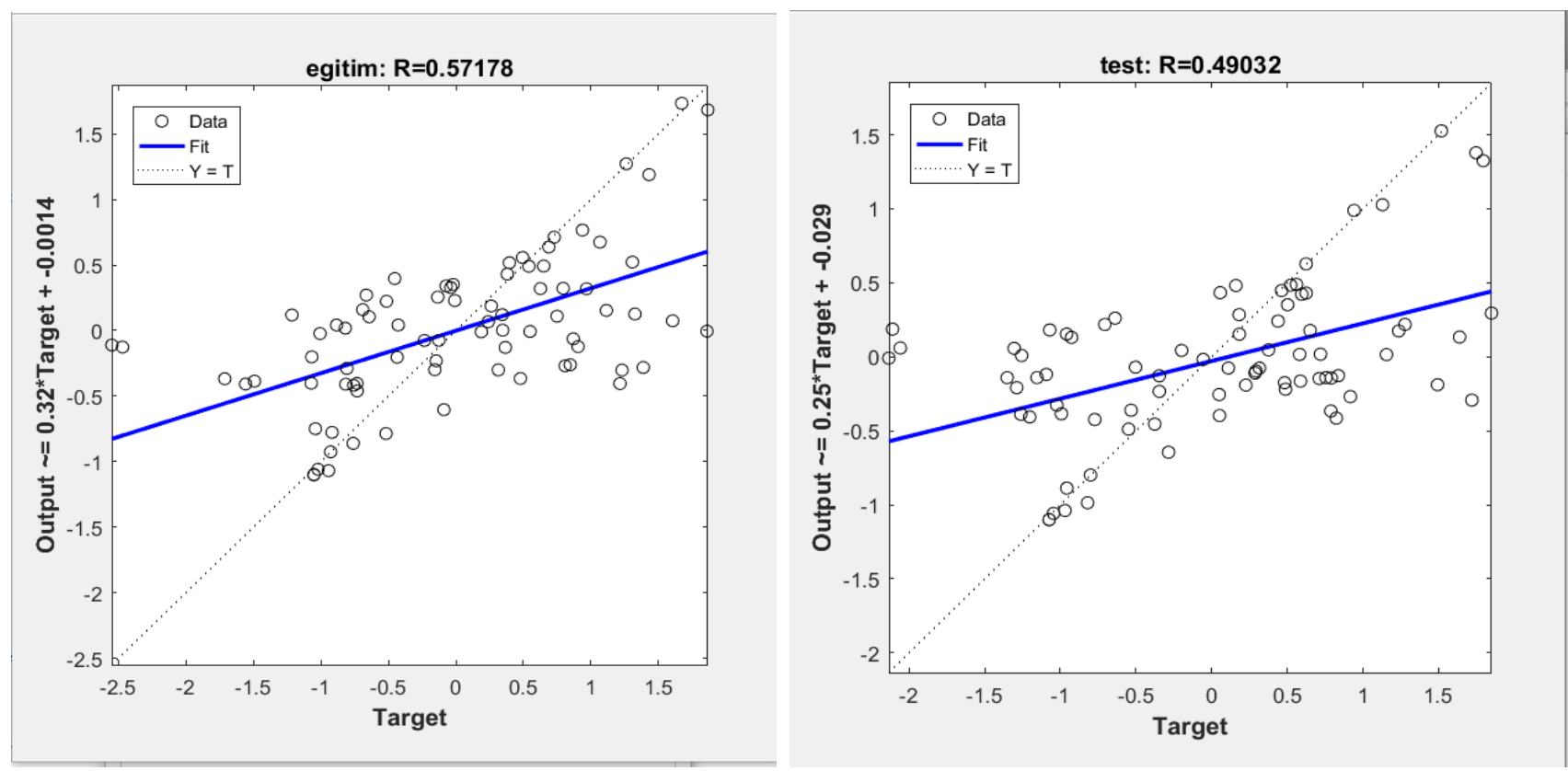

Şekil 8. Momentum Katsayılı Geriye Yayılım algoritmasının eğitilen model için tahmin değerleri 


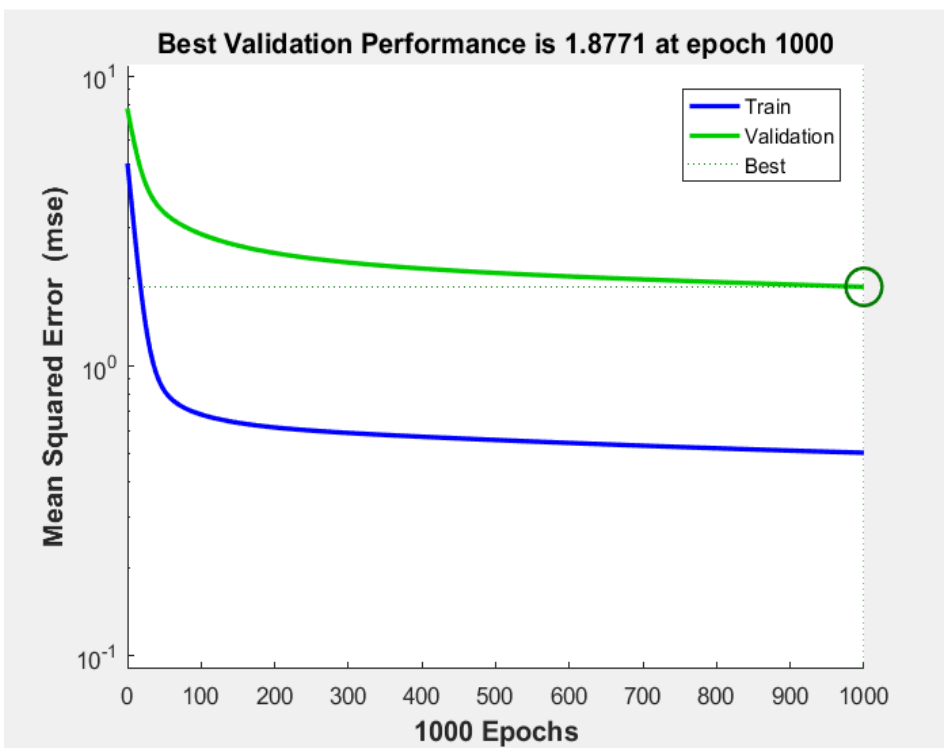

Şekil 9. Momentum Katsayılı Geriye Yayılım algoritmasının eğitilen model için doğrulama performansı

Şekil 9' da Momentum Katsayılı Geriye Yayılım algoritması ile eğitilen yapay sinir ağının en küçük kareler (MSE) yönteminde hesaplanmış minimum hata değeri gösterilmektedir. Çevrim sayısı arttıkça eğitim ve doğrulama tahminlerinin hata oranı aynı olmaktadır. En iyi doğrulama performansı ise 1000 çevrim için 1.8771' dir.

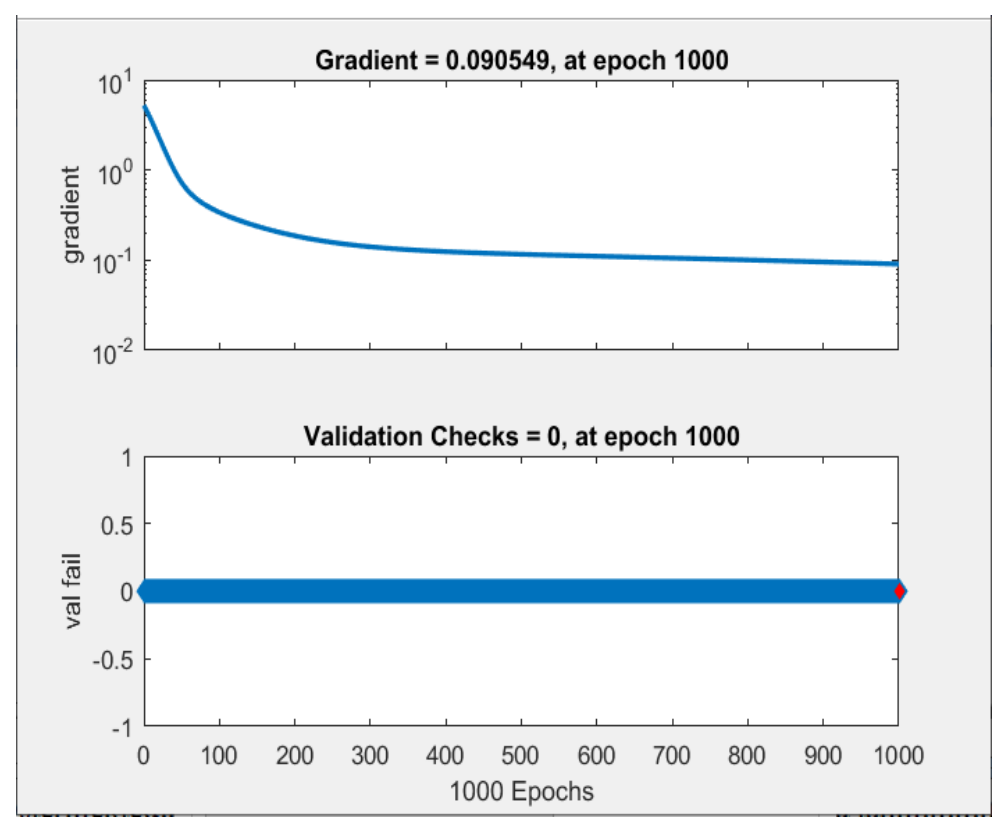

Şekil 10. Momentum Katsayılı Geriye Yayılım algoritmasının eğitilen model için gradyant ve başarısız doğrulamanın çevrim sayısına bağlı değişimi

Şekil 10'da görüldüğü gibi gradyant, maksimum çevrim sayısı 1000 için 0.090549 olmaktadır. Başarısız doğrulama ise 0'dır. 

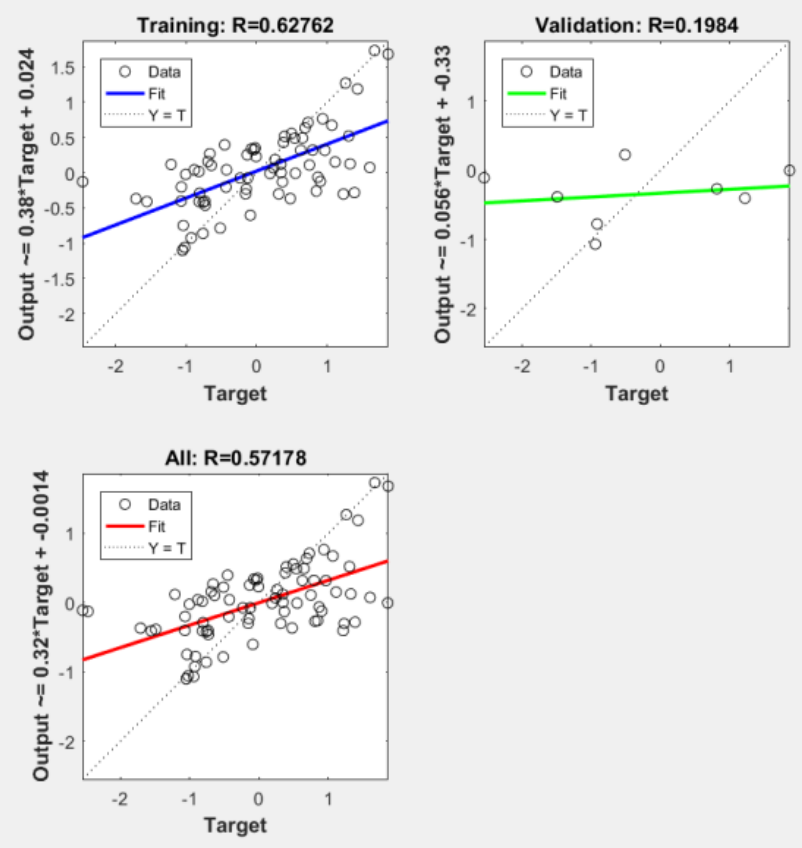

\section{Şekil 11. Momentum Katsayılı Geriye Yayılım algoritmasının eğitilen model için tüm tahmin değerleri}

Şekil 11'de Momentum Katsayılı Geriye Yayılım algoritması ile eğitilen model için tüm tahmin değerlerini göstermektedir ve çıkış verilerimizin tahmininde en iyi hedeflenen eğitim değeri 0.62762 , doğrulama tahmin değeri 0.1984 'tür. Eğitilmiş modelin istenilen seviyede olmadığı görülmüştür.
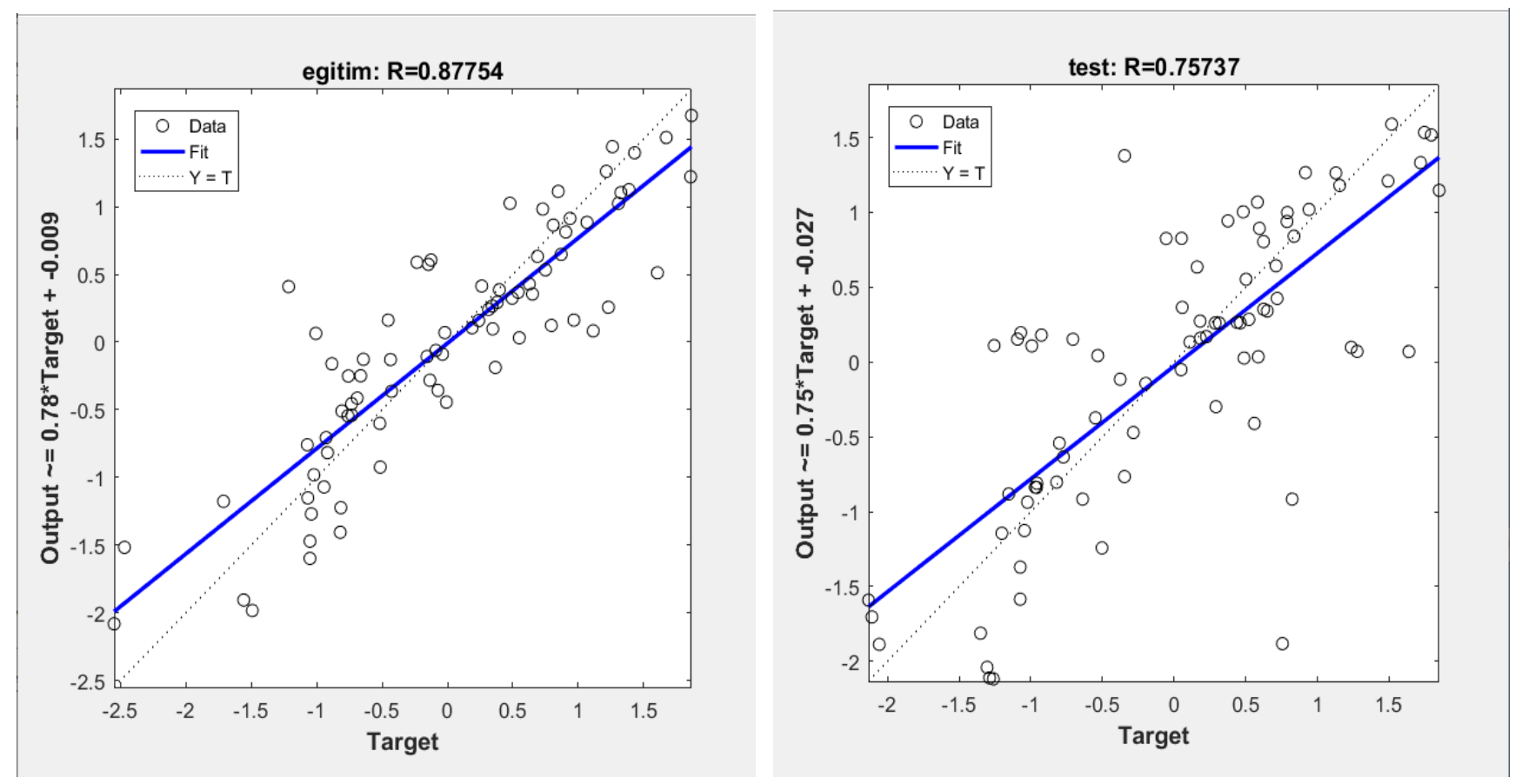

Şekil 12. Quasi-Newton Algoritmasının eğitilen model için tahmin değerleri

Üçüncü eğitim algoritmamız olan Quasi-Newton algoritması kullanılarak oluşturduğumuz model için Şekil 12'de ağın tahmin değerleri gösterilmektedir. Bu çalışmadaki çıkış verilerimizin en iyi eğitim tahmin değeri 0.87754 ve test tahmin değeri 0.75737 olarak hesaplanmıştır. 


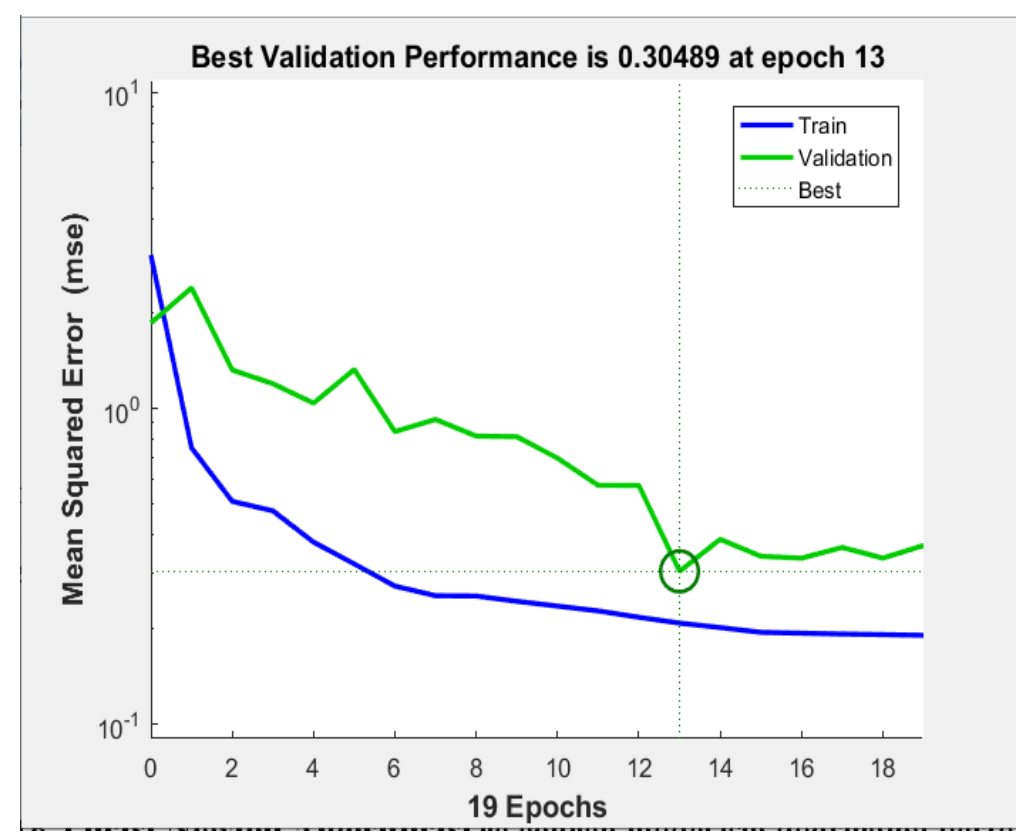

Şekil 13. Quasi-Newton Algoritmasının eğitilen model için doğrulama performansı

Şekil 13' de Adaptif Geriye Yayılım algoritması ile eğitim modeli için en küçük kareler yöntemi ile hesaplanmış minimum hata değerleri gösterilmektedir. Çevrim sayısı arttıkça eğitim ve doğrulama tahmin değerleri için hata oranları arasındaki fark azalmaktadır. En iyi doğrulama performansı ise 13 çevrim için $0,03609^{\prime}$ dur.

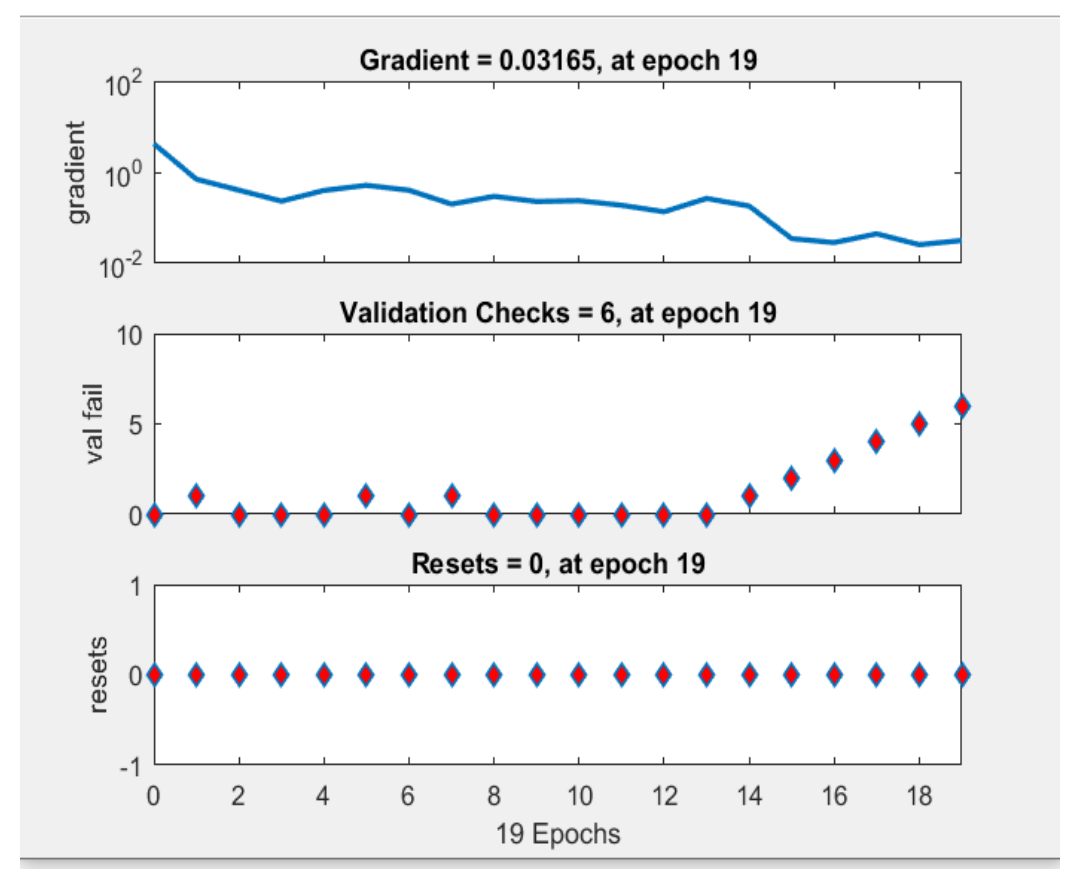

Şekil 14. Quasi-Newton Algoritması algoritmasının eğitilen model için gradyant, başarısız doğrulama ve sıfırlama katsayısının çevrim sayısına bağlı değişimi

Şekil 14 Quasi-Newton Algoritması ile eğitilen model için gradyant, başarısız doğrulama ve öğrenme katsayısının çevrim sayısına bağlı değişimini göstermektedir. Şekilde görüldüğü gibi eğitilen modelin çevrim sayısı 19 olmak üzere gradyant 0.03165 , başarısız doğrulama sayısı 6 ve sıfırlama katsayısı 0 olmaktadır. 

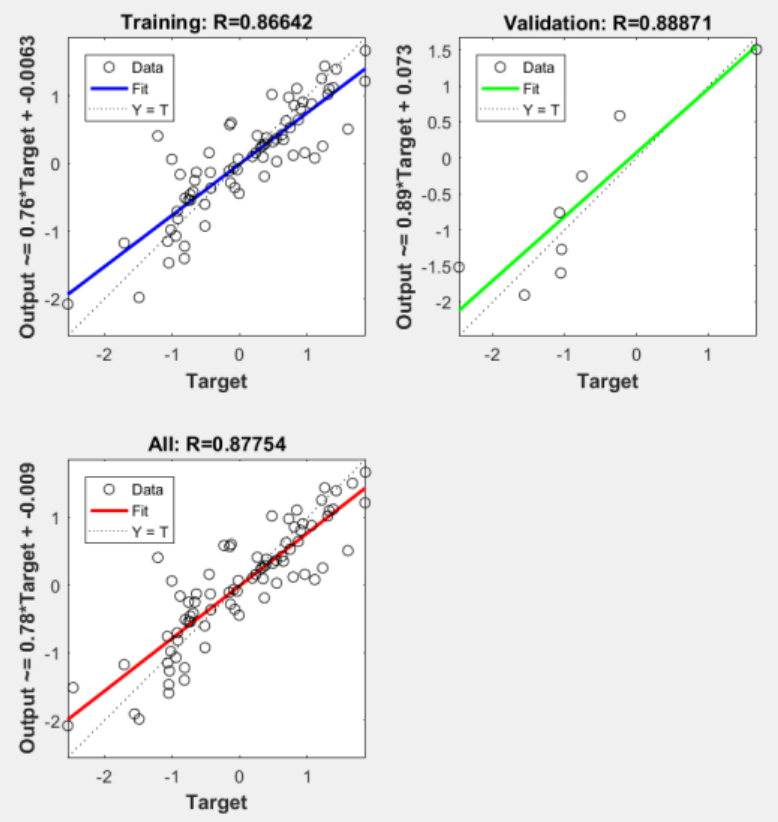

Şekil 15. Quasi-Newton Algoritmasının eğitilen model için tüm tahmin değerleri

Şekil 15'de Quasi-Newton Algoritması ile eğitilen model için tüm tahmin değerlerini göstermektedir. Bu model için çıkış verilerimizin en iyi eğitim tahmini 0.86642 ve en iyi doğrulama tahmin değeri 0,87754 olmaktadır. Quasi-Newton Algoritması ile eğitilen model de toplam tahmin değeri 0.87754 'dür.

Tablo 1. Eğitim Algoritmaları İçin Çevrim Sayısı

\begin{tabular}{|c|c|}
\hline & Çevrim Sayıs \\
\hline Geriye Yayılım algoritması (GY) & 1000 \\
\hline $\begin{array}{c}\text { Momentum Katsayllı Geriye Yayılım } \\
\text { algoritması(MGY) }\end{array}$ & 1000 \\
\hline Quasi-Newton Algoritması(QN) & 19 \\
\hline
\end{tabular}

Tablo 1' de eğitim algoritmalarının maksimum çevrim sayısı gösterilmektedir. Tablo incelendiğinde en az çevrim değerinde olan Quasi-Newton Algoritmasıdır. Eğitim algoritmalarından çıkan sonuçlar ile sayısal çözümlemeden elde edilen gerçek değerler ile tahmini değerler arasındaki hata değerlerinin minimumu, maksimumu ve ortama mutlak değerleri Tablo 2, Tablo 3, Tablo 4'de karşılaştırılmıştır.

Eşdeğer Gerilme Değerinin En Büyüğünün En Büyüğü olan değerin YSA'daki eğitilmiş modellerimiz olan Geriye Yayllım (GY), Momentumlu Geriye Yayılım (MGY), Quasi-Newton (QN) Algoritmalarının ürettikleri tahmini değerlerin gerçek değerlere ne kadar yakınsadığının bulmak açısından Tablo 2'de değerlendirilmiştir. Sonlu faklar metodunda ürettiğimiz 40 farklı kompozisyonel gradyant üst değeri eğitilmiş modele sunularak bu değerler arasındaki minimum hata, maksimum hata ve tüm hata değerlerini kapsaması açısından Ortalama Mutlak Hata (MAE) fonksiyonunda değerlendirilmiştir. Bu değerlere bakıldığında minimum hata değerinin Quasi-Newton Algoritması'nın (QN) 1.408117 değerinde, maksimum hata değerinin Geriye Yayılım Algoritması'nın (GY) 459.1461 değerinde ve en iyi Ortalama Mutlak Hata (MAE) Quasi-Newton Algoritması'nın (QN) 48.80017 değerinde olduğu görülmektedir. 
Tablo 2. Eşdeğer Gerilme Değerinin En Büyüğünün En Büyüğü Minimum Hata, Maksimum Hata ve Ortama Mutlak Hata Değerleri

\begin{tabular}{|c|c|c|c|}
\hline \multicolumn{4}{|c|}{$\sigma_{\text {eqv } \max \max }$} \\
\hline & GY & MGY & QN \\
\hline MiN & 2.764089 & 5.152502 & 1.408117 \\
\hline MAX & 459.1461 & 449.9309 & 137.918 \\
\hline MAE & 103.2441 & 129.0702 & 48.80017 \\
\hline
\end{tabular}

Tablo 3'de Eşdeğer Gerilme Değerinin En Büyüğünün En Küçüğü olan değerin eğitilmiş modellerdeki durumları incelenmiştir. Değerlere bakıldığında minimum hata değerinin Quasi-Newton Algoritması'nın (QN) 0.000014 değerinde, maksimum hata değerinin Momentum Geriye Yayılım Algoritması'nın (MGY) 0.493172 değerinde ve en iyi Ortalama Mutlak Hata (MAE) QuasiNewton Algoritması'nın (QN) 0.095004 değerinde olduğu görülmektedir.

Tablo 3. Eşdeğer Gerilme Değerinin En Büyüğünün En Küçüğü Minimum Hata, Maksimum Hata ve Ortama Mutlak Hata Değerleri

\begin{tabular}{|c|c|c|c|}
\hline \multicolumn{4}{|c|}{$\sigma_{\text {eqv } \max \min }$} \\
\hline & GY & MGY & QN \\
\hline MiN & 0.000759 & 0.017464 & 0.000014 \\
\hline MAX & 0.435858 & 0.493172 & 0.235007 \\
\hline MAE & 0.165866 & 0.184669 & 0.095004 \\
\hline
\end{tabular}

Eşdeğer Gerilme Değerinin En Küçüğünün En Küçüğü olan değerin eğitilmiş modellerdeki analiz değerleri Tablo 4'de gösterilmektedir. Değerlere bakıldığında minimum hata değerinin Geriye Yayılım Algoritması'nın (GY) 0.000001 değerinde, maksimum hata değerinin Geriye Yayılım Algoritması'nın (GY) 0.003548 değerinde ve en iyi Ortalama Mutlak Hata (MAE) Momentumlu Geriye Yayılım Algoritması'nın (MGY) 0.000787 değerinde olduğu görülmektedir.

Tablo 4. Eşdeğer Gerilme Değerinin En Küçüğünün En Küçüğü Minimum Hata, Maksimum Hata ve Ortama Mutlak Hata Değerleri

\begin{tabular}{|c|c|c|c|}
\hline \multicolumn{4}{|c|}{$\sigma_{\text {eqv } \min \text { min }}$} \\
\hline & GY & MGY & QN \\
\hline MiN & 0.000001 & 0.000043 & 0.000029 \\
\hline MAX & 0.003548 & 0.002685 & 0.003124 \\
\hline MAE & 0.000948 & 0.000787 & 0.000866 \\
\hline
\end{tabular}

\section{Sonuçlar}

YSA yöntemi ile FKM'de termo-mekanik davranışın en önemli kriteri olan eş değer gerilme değerinin, mevcut sınır koşulları altında, en iyi tahmin değerlerine ulaşılmaya çalışılmıştır. Yapılan çalışmada MATLAB [22] programlama dilinde 3 farklı nöronlu tek katmanlı algılayıcı model oluşturulan ve üç farklı eğitim algoritması için analizler gerçekleştirilmiştir. Ortalama Mutlak Hata (MAE), minimum hata, maksimum hata değerleri açısından modellerin eğitim ve test performansına bakıldığında genel olarak Quasi-Newton Algoritması diğer algoritmalara göre daha iyi sonuç çıkarmıştır. Geriye Yayılım ile Momentumlu Geriye Yayılım Algoritması'nda ise çalışma mantıkları benzer olduğu için değerler birbirine yakın çıkmıştır. Bu algoritmaların problemimizi analiz etme sürecinde performansları düşük kalmıştır. Dairesel plakanın radyal yapısından dolayı en büyüğünün en küçüğü olan eşdeğer gerilme değeri hep aynı çıktığından ve tüm eğitim algoritmaları doğru sonuca ulaştığından dolayı grafiklerde gösterilmemiştir. Kurulan modellerde CPU sürelerini azaltmak ve doğru veriye ulaşmak amaçlanmıştır. Termal gerilme probleminin Sonlu farklar metodu ile çözümü bir $n$ ve m değerine yaklaşı 302400 saniye sürerken, model kurulduktan sonra bu değere 1 saniyeden k1sa sürede ulaşılmaktadır. 


\section{Referanslar}

[1] Koizumi M. and Niino M., "Overview of FGM research in Japan”, MRS Bulletin, vol.20, no.1,pp.19-21, 1995. DOI: https://doi.org/10.1557/S0883769400048867

[2] Ruys A., Popov E., Sun D., Russell J., and Murray C., "Functionally graded electrical/thermal ceramic systems.". Journal of the European Ceramic Society, vol.21,no.10- 11,pp.2025 - 2029, 2001.

[3] Shabana Y.M. and Noda N., "Thermo-elastic-plastic stresses in functionally graded materials subjected to thermal loading taking residual stresses of the fabrication process into consideration", Composites Part B: Engineering, vol.32, no.2, pp.111-121, 2001. DOI: $10.1016 / \mathrm{S} 1359-8368(00) 00049-4$

[4] Boğa C., "Elastic Analysis of an Hollow Cylinder Made from Functionally Graded Material Exposed to Internal Pressure’'International Scientific and Vocational Studies Journal, vol.2 ,no.1, pp.56 - 66, 2018.

[5] Wang Q. ,Li Q, Wu D, Yu Y,Tin-Loi F, Ma J ,Gao W, “ Machine learning aided static structural reliability analysis for functionally graded frame structures", Applied Mathematical Modelling , vol.78 ,pp.792-815, 2020. https://doi.org/10.1016/j.apm.2019.10.007

[6] Do D.T.T. ,Nguyen-Xuan H. ,Lee J., “ Material optimization of tri-directional functionally graded plates by using deep neural network and isogeometric multimesh design approach", Applied Mathematical Modelling,vol. 87 ,pp.501-533,2020.

[7] Ghatage P.S.,Kar V.R., P., Sudhagara E., " On the numerical modelling and analysis of multi-directional functionally graded composite structures: A review”,Composite Structures, vol.236 ,pp.111837, 2020.

[8] Karsh P.K,Mukhopadhyay T., Dey S., "Stochastic dynamic analysis of twisted functionally graded plates", Composites Part B,vol. 147 ,pp.259-278, 2018.

[9] Dikici B and Tuntas R., "An artificial neural network (ANN) solution to the prediction of age-hardening and corrosion behavior of an Al/TiC functional gradient material (FGM), Journal of Composite Materials, 0(0) 1-15,2020.

[10] Mantari J.L. and Monge J.C., "Buckling. free vibration and bending analysis of functionally graded sandwich plates based on an optimized hyperbolic unified formulation", International Journal of Mechanical Sciences,vol.119, pp.170-186, 2016.

[11] Nazari F., Abolbashari M.H., Hosseini S.M., “ Three Dimensional Natural Frequency Analysis of Sandwich Plates with Functionally Graded Core Using Hybrid Meshless Local Petrov-Galerkin Method and Artificial Neural Network'. CMES, vol.105 no.4,pp.271-299, 2015.

[12] Jodaei A., Jalal M.,Yas M.H., "Free vibration analysis of functionally graded annular plates by state-space based differential quadrature method and comparative modeling by ANN", Composites: Part B , vol.43,pp. 340-353, 2012.

[13] Cho J.R., Ha D.Y., " 'Optimal tailoring of 2D volume-fraction distributions for heat-resisting functionally graded materials using FDM’, Computer Methods in Applied Mechanics and Engineering, vol.191, no:29-30, pp.3195-3211, 2002.

[14] Na K.S., Kim J.H., "Volume fraction optimization for step-formed functionally graded plates considering stress and critical temperature”, Composite Structures, vol.92, no.6, pp.1283-129092:1283-1290, 2010.

[15] Cho J.R. and Shin S.W., "Material composition optimization for heat-resisting FGMs by artificial neural network", Composites Part A: Applied Science and Manufacturing, vol.35, no:5, pp.585-594, 2004.

[16] Demirbaş M. D., Çakır D. “Thermal Stress Analysis in Two-Directional Functionally Graded Plates with Artificial Neural Network Training Algorithms", International Journal of Engineering Research and Development vol.11, no.2, pp.442-450, 2019.

[17] Demirbaş M. D., Çakır D., Arslan S., Öztürk C “.Equivalent stress analysis of functionally graded rectangular plates by genetic programming International Scientific and Vocational Studies Journal, vol.2, pp.67-80, 2018.

[18] Çakır D.,Demirbaş M. D., "Modelling of One-directional Functionally Graded Circular Plates with Artificial Neural Network”, International Scientific and Vocational Studies Journal, vol.3,no.1,pp.42-50, 2019. 
[19] Apalak M.K., Demirbaş M.D., “'Improved Mathematical Models of Thermal Residual Stresses in Functionally Graded Adhesively Bonded Joints: A Critical Review”, ,Reviews of Adhesion and Adhesives, vol. 7,no.4,pp.367-416, 2019.

[20] Demirbaş M.D. , SOFUOĞLU D. “Thermal Stress Control in Functionally Graded Plates with Artificial Neural Network, International Scientific and Vocational Studies Journal,vol.2, no.1, pp.39-55, 2018.

[21] Demirbaş M. D., “Düzlem İçi Issıl Yüke Maruz Tek Yönlü İşlevsel Kademelendirilmiş Plaka ve Disk Bağlantılarının Issıl Gerilme Analizi', Erciyes Üniversitesi, Fen Bilimleri Enstitüsü, Makine Mühendisliği, Yüksek Lisans, 2009.

[22] MATLAB. Mathematical software, version 2009a, TheMathWorks.Available: http://www.mathworks.com.7

[23] Apalak M. K. , Demirbaş M. D. “Thermal Residual Stresses İn İn-Plane Functionally Graded Clamped Hollow Circular Plates', Subjected To An Edge Heat Flux Proceedings Of The Institution Of Mechanıcal Engineers Part L-Journal Of MaterialsDesign And Applications, Cilt:229, s236-260, 2015.

[24] Apalak M. K. , Demirbaş M. D. “ 'Thermal residual stresses in adhesively bonded in-plane functionally graded clamped circular hollow Plates', Journal Of Adhesion Science And Technology, vol.27, pp.1590-1623, 2013.

[25] Demirbaş M.D., "Düzlem İçi Isıl Yüke Maruz İki Yönlü Kademelendirilmiş Dikdörtgen ve Dairesel Plakaların Isıl Gerilme Analizi',,Erciyes Üniversitesi,Fen Bilimleri Enstitüsü. Doktora Tezi, Kayseri, 207s, 2012.

[26] Mori, T., Tanaka, K., “ Average stress in matrix and average elastic energy of materials with misfittings inclusions.” Acta Metallurgica, 21(5): 517-574, 1973.

[27] Nemat-Alla, M., Ahmed, K.I.E., Hassab-Allah, I., "Elastic-plastic analysis of two-dimensional functionally graded materials under thermal loading', International Journal of Solids and Structures, vol.46, no.14-15,pp.2774-2786, 2009.

[28] M. Luy, U. Saray, "Wind speed estimation for missing wind data with three different backpropagation algorithms," Energy Education Science and Technology Part A: Energy Science and Research, vol. 30, no. 1, pp. 45-54, 2012.

[29] Metrotra K., Mohan C.K., Ranka S., “ Elements of artificial neural networks, 1997.

[30] Güler H., “'Çinko-Alüminyum Alaşımlarının Korozyon Davranışına Alaşım Elementlerinin Etkisinin Yapay Sinir Ağıyla Tahmini’’.Sakarya Üniversitesi Fen Bilimleri Enstitüsü,Yüksek Lisans,Sakarya, 2007.

[31] Rumelhart, D.E., Hinton, G.E., Williams, R.J., “'Learning representations by backpropagation errors”, Nature, vol.323, pp.533-536, 1986.

[32] G.W. NG , “Application of Neural Networks to Adaptive Control of Nonlinear Systems”, 1997. 